\title{
Nitrosamine Metabolism
}

National Cancer Institute

\section{Source}

National Cancer Institute. Nitrosamine Metabolism. NCI Thesaurus. Code C20137.

Nitrosamine Metabolism involves important cellular biochemical detoxification reactions

that chemically modify the $\mathrm{N}$-nitroso derivatives of secondary amines, formed by the combination of nitrates with amines. Some nitrosamines show carcinog enic activity; under certain conditions, nitrite-containing foods can form nitrosamines. 